\title{
T-lymphocyte clones from leprosy skin lesions
}

\author{
R L MODLIN, G M GERSUK, E E NELSON, P K PATTENGALE, \\ J R GUNTER, L CHEN, CL COOPER, B R BLOOM \& T H REA \\ Section of Dermatology and Department of Pathology, University of \\ Southern California School of Medicine, Los Angeles, and Department \\ of Microbiology and Immunology, Albert Einstein College of \\ Medicine, Bronx, NY USA.
}

\section{Introduction}

The immune response of patients with leprosy to antigens of Mycobacterium leprae correlates with a spectrum based upon clinical and histopathologic categories (1). Patients at the tuberculoid pole have strong cell-mediated immune responses whereas, patients at the lepromatous pole are selectively unresponsive to antigens of $M$. leprae. The identification of epitopes recognized by lymphocytes from the resistant tuberculoid patients are important in designing an antileprosy vaccine. In addition, the mechanism of immune unresponsiveness of lepromatous patients is of fundamental importance in contributing to our understanding of immune tolerance in man (2).

The overwhelming majority of investigative studies into the immunology of leprosy has been performed on cells obtained from peripheral blood of patients. For example, Mehra et al. described lepromin-induced suppressor T-lymphocytes in lepromatous patients which were thought to contribute to the unresponsiveness of these patients (3-5). We have conf irmed these studies by measuring the effect of Dharmendra lepromin on the Concanavalin $\mathrm{A}$ (Con A) response of peripheral blood mononuclear cells (PBMC). We were able to demonstrate suppressor cell activity in lepromatous and borderline lepromatous patients, but not in tuberculoid patients, normals or contacts (6).

Mehra further demonstrated that suppressor T-lymphocytes could be induced to suppress PBMC Con A responses by phenolic glycolipid-l (PG-I) (7). In collaboration with Bloom and Brennan (8-10), we sought to define the epitope recognized by these suppressor cells. Suppression in lepromatous patients was observed with both synthetic terminal disaccharide and monosaccharide conjugated to bovine serum albumin. Thus it appears that the terminal sugar unit of PG-1 is the carbohydrate epitope recognized by T-suppressor cells from lepromatous patients.

In taking care of increasing numbers of patients at Los Angeles County Hospital, we recognize that leprosy is a disease of skin and nerves. The focal point of the immune response to $M$. leprae is the granuloma, a collection of lymphocytes and macrophages. Therefore, it is important to critically evaluate these cells in sites of disease activity.

\section{Immunopathology of Leprosy}

Phenotypic marker analysis of lymphocytes in skin lesions using monoclonal antibodies and immunoperoxidase techniques was performed. In tuberculoid leprosy lesions, T4 (helper/in- 
ducer) lymphocytes were more numerous than T8 (suppressor/cytotoxic) lymphocytes. Interestingly, suppressor lymphocytes were localized at the periphery of the granuloma. In lepromatous lesions, suppressor lymphocytes were more numerous than helper lymphocytes. These differences were not observed in the peripheral blood. The peripheral blood helper: suppressor ratio in tuberculoid and lepromatous patients was identical, about 2:1. Immunoperoxidase staining of tissues showed a 2:1 ratio in tuberculoid lesions and a 1:2 ratio in lepromatous lesions (11-14).

American cutaneous leishmaniasis forms a spectrum similar to that of leprosy in that patients with localized disease have strong cell-mediated responses, while those with disseminated disease are unresponsive. In collaboration with Jacinto Convit, we studied skin lesions of patients with leishmaniasis (15). Patients with disseminated leishmaniasis have a suppressor cell excess in lesions similar to patients with lepromatous leprosy. However, we were surprised to find that patients with localized leishmaniasis, in direct contrast to those with tuberculoid leprosy, also had a suppressor/cytotoxic T8+ cell excess in lesions.

It was evident that T-lymphocyte phenotype alone was not sufficient to explain the immunopathogenesis of tissue lesions. Therefore, we sought to examine more specific markers of immune function (16). Tac or interleukin-2 receptor bearing cells were present in similar numbers in all forms of leprosy and leishmaniasis. We then used a monoclonal antibody against IL-2 which identified large cells with cytoplasmic staining. These cells on double staining were found to be helper/inducer T-cells, not suppressor/cytotoxic T-cells and did not bear Il-2 receptors. These cells were most probably IL-2 producing cells and could occasionally be located near OKT6+ Langerhans cells which can present antigen, Quantitation of IL-2 + cells in skin lesions revealed a striking association with the strength of the cell-mediated response. There were ten times the numbers of IL-2 producing cells in tuberculoid leprosy as compared with lepromatous leprosy. Patients with localized leishmaniasis had greater numbers of IL-2+ cells in lesions than those with disseminated disease. Therefore, examination of molecules closely associated with immune function is more specifically related to the immune response.

Langerhans' cells which are intraepidermal antigen-presenting cells, are more numerous in tuberculoid leprosy than lepromatous leprosy $(11,17)$. In addition, we reported in 1983 that keratinocyte expression of Ia antigen was present in tuberculoid but not lepromatous leprosy (11). Nathan et al have demonstrated the relationship of keratinocyte la expression to interferon-gamma production (18).

\section{T-helper lymphocytes from tuberculoid lesions}

Patient skin lesions seemed an ideal location to obtain immune cells reactive to $M$. leprae for study: 1) Cells in lesions would be easy to grow in culture because they are already activated $(\mathrm{Tac}+)$ in situ. 2) Cells in lesions should be concentrated for reactivity against $M$. leprae. 3) We decided to clone cells from lesions instead of peripheral blood because cell populations in the lesions were phenotypically different and therefore likely to be functionally differant than in the peripheral blood. 4) Finally, cloning cells from lesions would provide homogenous populations of immune cells for functional study.

Skin biopsy specimens were obtained from untreated patients with leprosy and extruded through a surgical steel mesh (19). A single cell suspension was then labelled with monoclonal antibodies and analyzed and sorted with a FACS IV. T-cell lines were established or the lymphocytes were cloned by limiting dilution in the presence of interleukin- 2 and irradiated PBMC, or for T4 cells in the presence of antigen as well. We are confident that with these methods, we obtained lymphocytes derived from skin lesions and not from blood vessels within lesions. The helper to suppressor ratios were in agreement with those obtained by 
immunoperoxidase and in the case of lepromatous patients, different than the peripheral blood ratio.

T4 clones from tuberculoid lesions were assayed for proliferative responses to both lepromin and PPD antigens. T-helper clones derived from tuberculoid lesions showed four patterns of reactivity. Several clones were lepromin specific in that they responded strongly to lepromin, but only weakly to PPD. Several clones were reactive to epitopes shared by both $M$. leprae and $M$. tuberculosis. Some clones reacted more strongly to PPD, although weakly. A few clones were IL-2 dependent but did not proliferate in response to antigen.

Several of these T4 clones were studied more closely for species specificity against a panel of different species of mycobacteria. Again, M. leprae specific clones were present in lesions. Clones were also identified which were crossreactive with most mycobacteria and those that were cross reactive with few mycobacteria. We have now assayed 62 clones from lesions of 3 tuberculoid patients. About half the clones are $M$. leprae specific, while half are cross reactive. It may be that both specific and cross reactive epitopes are important in the immune protection that these patients have.

To follow on the role of interferon-gamma in tuberculoid lesions, we assayed an $M$. leprae specific clone for interferon-gamma production by radioimmunoassay. This clone was able to proliferate and produce interferon-gamma in response to $M$. leprae but not $M$. tuberculosis. T4 lymphocytes from lepromatous lesions grown in an identical manner have so far proven to be unresponsive to $M$. leprae antigens.

\section{T-suppressor lymphocytes from lepromatous lesions}

T8 lines or clones were assayed for lepromin-induced suppression of the peripheral blood Con A response. Normal PBMC were cocultured with the T8 line or clone in the presence or absence of lepromin and Con A. Percent suppression was caluculated as the difference between triplicate cultures in the presence versus the absence of lepromin.

In $1 / 3$ of the lines derived from lesions of 6 lepromatous patients, significant suppression was observed. In the remaining $2 / 3$ of the lines from lepromatous lesions, no suppression was observed. In addition, in the 9 lines obtained from 6 tuberculoid patients lepromin-induced suppression could not be demonstrated. In four of the lines tested that were triggered to suppress by lepromin, no suppression was induced by tetanus toxoid, an indication of antigen specificity (19).

Some lines appeared to suppress some donors but not others. To investigate whether a genetic restriction could explain this observation, 2 T8 suppressor clones were established from 2 lepromatous patients, HLA-DR type [4,-] and [4,1]. These clones were assayed for lepromin-induced suppression of the con A response of 6 normal donors, three shared the HLA-DR [4] type and three were mismatched (20). When the first T8 clone was assayed with the class II MHC matched donors, suppression was observed. When this clone was assayed with the class II MHC mismatched donor, no suppression was observed. The second T8 clone also suppressed only when assayed with PBMC sharing class II antigens. There was no correlation with class I MHC. A T4 clone was used to control for the addition of cells and possible competition for IL-2 in the medium. No suppression was observed when this T4 clone was assayed with either matched or mismatched PBMC.

Because the biological significance of suppression of a mitogen response is unclear, we wished to ask the question: can these $\mathrm{T} 8$ clones suppress the antigen response of lepromin reactive $\mathrm{T} 4$ clones? To these $\mathrm{T} 4$ clones we added irradiated antigen presenting cells and lepromin and then assayed for thymidine incorporation in the the presence or absence of the T8 or control nonreactive T4 clones. The T8+ clones were able to suppress the lepromin response of the class II MHC matched but not mismatched T4 clone. Again, the T4 control clo- 
ne had no effect. A summary of the data demonstrating the MHC class II restriction is shown in Figure 1.

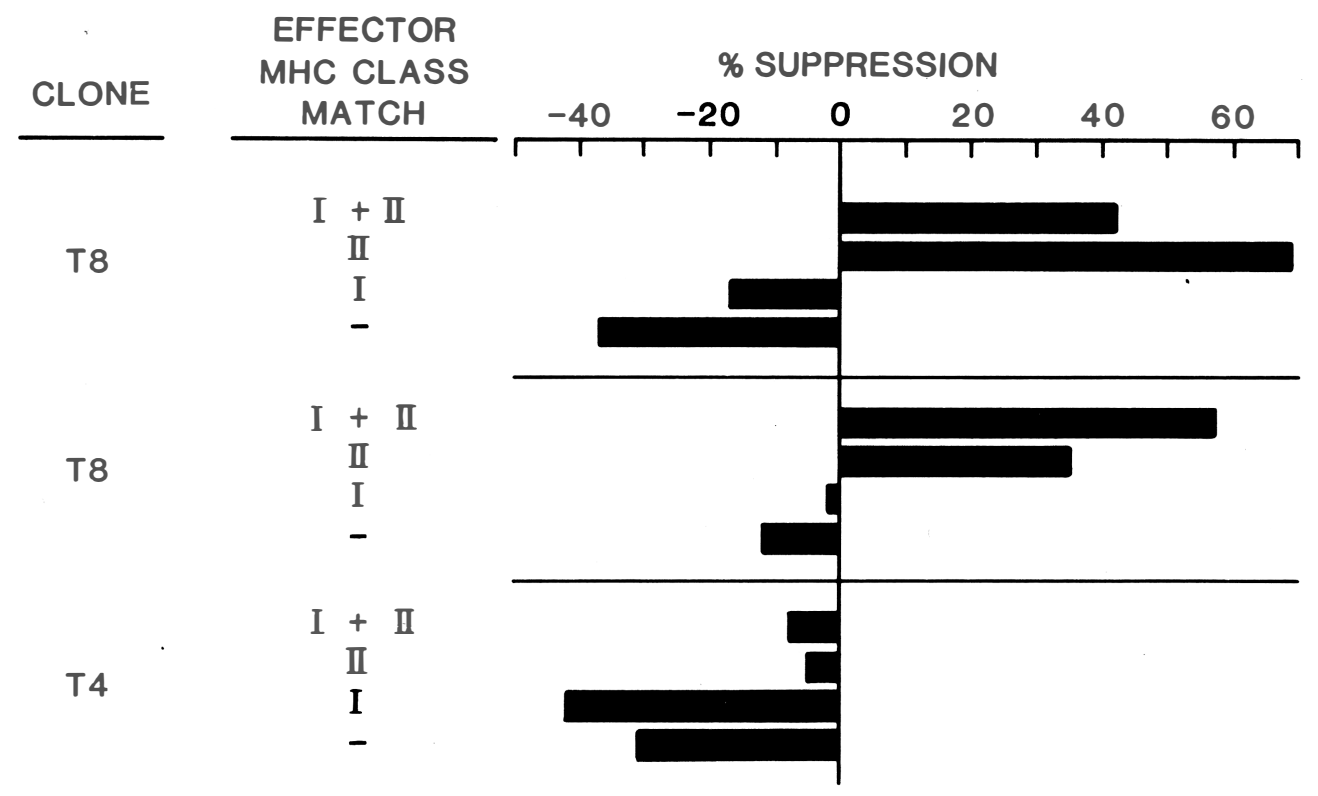

Figure 1.

In conclusion, cloned suppressor T-cells derived from lepromatous leprosy skin lesions can be triggered by lepromin to suppress the con A response of normal PBMC. These suppressor $\mathrm{T}$-cell clones can suppress the proliferative response of helper $\mathrm{T}$-cell clones to lepromin. This suppression is probably restricted by class II MHC antigens. Therefore, the unresponsiveness of lepromatous leprosy patients to antigens of $M$. leprae may be related to the presence of these suppressor T-cells within lesions, perhaps by inhibiting Il-2 production.

These methods provide a new means to study the immune response of patients to infection, neoplasia and autoimmune disease at the tissue level. In addition, the helper and suppressor clones from leprosy skin lesions can be used to elucidate the range of cloned antigens and epitopes recognized by the T-lymphocyte repertoire in leprosy.

\section{Acknowledgments}

Supported by grants from the the National Insitutes of Health (AI 22187 and 22553), the UNDP/World Bank/World Health Organization Special Programme for Research and Training in Tropical Diseases (IMMLEP), National Hansen's Disease Center, Knights of St. Lazarus of Jerusalem, Heiser Trust, and the Hartford Foundation.

\section{References}

1 Ridley DS. Histological classification and the immunological spectrum of leprosy. Bull WHO, 1974; 51: 451.

2 Bloom BR, Mehra V. Immunological unresponsiveness in leprosy. Immunol Rev, 1984; 80: 5 .

3 Mehra V, Mason LH, Fields JP, Bloom BR. Lepromin-induced suppressor cells in patients with leprosy. J Immunol, 1979; 123: 1813. 
4 Mehra V, Mason LH, Rothman W, Reinherz E, Schlossman SF, Bloom BR. Delineation of a human $\mathrm{T}$ cell subset responsible for lepromin-induced suppression in leprosy patients. J Immunol, 1980; 125: 1183.

5 Mehra V, Convit J, Rubinstein A, Bloom BR. Activated suppressor T cells in leprosy. J Immunol, 1982; 129: 1946.

6 Modlin RL, Mehra V, Jordan R, Bloom BR, Rea TH. In situ and in vitro characterization of the cellular immune response in erythema nodosum leprosum. J Immunol, 1986; 136: 883.

7 Mehra V, Brennan PJ, Rada E, Convit J, Bloom BR. Lymphocyte suppression in leprosy induced by unique M. leprae glycolipid. Nature, 1984; 308: 194.

8 Chatterjee D, Douglas JT, Cho S-N, Rea TH, Gelber RH, Aspinall GO, Brennan PJ. Synthesis of neoglycoproteins containing the 3,6-di-O-methyl-beta-D-glucopyranosyl epitope and their use in the serodiagnosis of leprosy. Glycoconjugate J, 1985; 2: 187.

9 Cho SN, Chatterjee D, Brennan PJ. A simplified serological test for leprosy based on a 3,6-di-O-methylglucose-containing synthetic antigen. Am J Trop Med Hyg, 1986; 35: 167.

10 Chatterjee D, Cho S-N, Brennan PJ. chemical synthesis and seroreactivity of O-(3,6-di-O-methyl-beta-D-glucopyranosyl)-(1-4)-O-(2,3-di-O-methyl-alpha-Lrhamnopyranosyl)-(1-9)-oxynonanoyl-bovine serum albumin - the leprosy specific natural disaccharide-octyl-neoglycoprotein. Carbohydr Res, 1986; 155: in press.

11 Modlin RL, Hofman FM, Taylor CR, Rea TH. T lymphocyte subsets in the skin lesions of patients with leprosy. J Am Acad Dermatol, 1983; 8: 182.

12 Modlin RL, Hofman FM, Meyer PR, Sharma OP, Taylor CR, Rea TH. In situ demonstration of $\mathrm{T}$ lymphocyte subsets in granulomatous inflammation: leprosy, rhinoscleroma and sarcoidosis. Clin exp Immunol, 1983; 51: 430.

13 Modlin RL, Gebhard JP, Taylor CR, Rea TH. In situ characterization of T lymphocyte subsets in the reactional states of leprosy. Clin exp Immunol, 1983; 53: 17.

14 Modlin RL, Bakke AC, Vaccaro SA, Horwitz DA, Taylor CR, Rea TH. Tissue and blood T-lymphocyte subpopulations in erythema nodosum leprosum. Arch Dermatol, 1985; 121: 216.

15 Modlin RL, Tapia FJ, Bloom BR, Gallinoto ME, Castes M, Rondon AJ, Rea TH, Convit J. In situ characterization of the cellular immune response in American cutaneous leishmaniasis. Clin exp Immunol, 1985; 60: 241.

16 Modlin RL, Hofman FM, Horwitz DA, Husmann LA, Gillis S, Taylor CR, Rea TH. In situ identification of cells in human leprosy granulomas with monoclonal antibodies to interleukin 2 and its receptor. J Immunol, 1984; 132: 3085.

17 Modlin RL, Rowden G, Taylor CR, Rea TH. Comparison of S- 100 and OKT6 antisera in human skin. J Invest Dermatol, 1984; 83: 206.

18 Nathan CF, Kaplan G, Levis WR, Nusrat A, Witmer MD, Sherwin SA, Job CK, Horowitz CR, Steinman RM, Cohn ZA. Local and systemic effects of intradermal recombinant interferon-gamma in patients with lepromatous leprosy. N Engl J Med, 1986; 315: 6.

19 Modlin RL, Mehra V, Wong L, Fujimiya Y, Chang W-C, Horwitz DA, Bloom BR, Rea TH, Pattengale PK. Suppressor T lymphocytes from lepromatous leprosy skin lesions. J Immunol, 1986; 137: 2831.

20 Modlin RL, Kato H, Mehra V, Nelson EE, Xue-dong F, Rea TH, Pattengale PK, Bloom BR. Genetically restricted suppressor T-cell clones derived from lepromatous leprosy lesions. Nature, 1986; 322: 459. 